\title{
Enlightenment for Future Nursing Education from Evaluating Perception of Competencies of Doctor of Nursing Practice Programs
}

\author{
Baoxiang Wang ${ }^{1}$, Elizabeth Roe ${ }^{2}$, Weiju Chen ${ }^{1, *}$, Judith Ruland $^{2}$ \\ ${ }^{1}$ College of Nursing, Jinan University, Guangzhou, China \\ ${ }^{2}$ College of Health and Human Service, Saginaw Valley State University, Michigan, United State \\ Email address: \\ 15876584927@163.com (Baoxiang Wang),eroe@svsu.edu (E. Roe),weijuchen2008@163.com (Weiju Chen), \\ jruland@svsu.edu (J. Ruland) \\ ${ }^{*}$ Corresponding author
}

\section{To cite this article:}

Baoxiang Wang, Elizabeth Roe, Weiju Chen, Judith Ruland. Enlightenment for Future Nursing Education from Evaluating Perception of Competencies of Doctor of Nursing Practice Programs. American Journal of Nursing Science. Vol. 10, No. 2, 2021, pp. 118-123.

doi: 10.11648/j.ajns.20211002.11

Received: February 15, 2021; Accepted: February 23, 2021; Published: March 3, 2021

\begin{abstract}
Lack of research still exists about how Doctor of Nursing Practice (DNP) prepared nurses meet the AACN Essentials of Doctoral Education for Advanced Nursing Practice. The goal of this study was to examine the perception of DNP prepared nurses and employers on how they met the AACN Essentials. Self-reported data was collected from a convenience sample of DNP prepared nurses and employers across the U.S. $(n=202)$ through an electronic survey assessment. Overall, the participants perceived that the DNP prepared nurses were meeting the competencies with all Essentials receiving a mean score above 4 (agree). The lowest mean score (4.289) was rated for Essential VII (Clinical Prevention and Population Health for Improving the Nation's Health). Two other low mean scores were 4.310 for Essential V (health care policy for advocacy in health care) and 4.360 for Essential IV (information systems/technology and patient-care technology for the improvement and transformation of health care). The perception that DNP prepared nurses rated for Essential III $(4.49 \pm .68, \mathrm{p}=.026)$, VI (4.48 $\pm .84, \mathrm{p}=.017)$, and the total Essentials $(4.43 \pm .67, \mathrm{p}=.023)$, and other employers rated for Essential VI $(4.02 \pm 1.17, \mathrm{p}=.042)$ were statistically significantly lower compared to those working as a DNP prepared nurse and an employer at the same time. The findings of this study have a number of important insights into the value of DNP prepared nurses for the future development of DNP programs in the U.S and the future initiation in other countries.
\end{abstract}

Keywords: Enlightenment, Nursing Education, Perception, Essentials, Competency, Doctor of Nursing Practice (DNP)

\section{Introduction}

The American Association of Colleges of Nursing (AACN) first introduced Doctor of Nursing Practice (DNP) programs in 2004 calling for these programs to prepare leaders for nursing practice at the highest level of nursing practice [1]. To specify the role of DNP prepared nurses, AACN created a task force outlining the Essentials of Doctoral Education for Advanced Nursing Practice which proposed eight core essentials to equip graduates to improve health care delivery and promote patient outcomes [2].

Evaluating the competencies of DNP prepared nurses has become significant because of the proliferation of DNP programs over the past 15 years, with 348 DNP programs enrolling students at schools of nursing nationwide in the U.S to date [3]. There is a lack of research regarding the outcomes of DNP prepared nurses and researchers have called for outcome studies of DNP practice to better understand the impact of these graduates on patient care [4]. Others have said it is time to consider the impact DNP graduates are having on individual patient care, population health, and the health care delivery system [5]. Furthermore, focusing future research efforts on quantifying the outcomes of DNP prepared nurses will provide important insight into the value of DNP prepared nurses across health care settings [6].

This study examined the self-perception of the 
competencies of DNP from both DNP prepared nurses and their employers. The findings provide valuable information to current DNP program development in the U.S. In addition, as other countries, including China, examine the usefulness of DNP prepared nurses, this information will be valuable to them [7]. To date, few DNP programs have been developed in China, though some universities in Hong Kong district have some similar doctoral nursing programs focused on practice but the titles of them were called Doctor of Nursing Programme. Many universities in China desire to promote their nursing practice to include DNP prepared nurses.

\section{Method}

\subsection{Study Design, Sample, and Setting}

This descriptive, quantitative study utilized an online survey to collect data from DNP prepared nurses and employers of DNP nurses. After approval by Saginaw Valley State University's Institutional Review Board, a convenience sample of DNP prepared nurses and their employers was recruited at the 2020 AACN Doctoral Education Conference and the websites of universities with DNP programs in the U.S.

\subsection{Competencies of DNP Prepared Nurses Survey Tool}

The survey used for this research was adapted from an electronic survey used to assess the value of DNP-APRNs in Texas [8]. Christiansen's survey was distributed to organizations, such as DNP Inc., National Association of Pediatric Nurse Practitioners (NAPNAP), Texas Nurse Practitioners (TNP), Texas Austin Chapter of NAPNAP, Austin Advanced Practice Nurses and Facebook groups. The sample for this study was mostly pediatric and regional sampling of nursing practitioners. The respondents $(\mathrm{N}=113)$ described how frequently they engaged in each DNP-APRN competency item in one week using a 5-point Likert scale with 5 to 1 indicating "all the time" to "never".

The study described in this article partially replicated Christianson and Champion's study and expanded the survey to include all DNP prepared nurses (versus just APRNs) and their employers functioning in all roles across the U.S. The intent of this Competencies of DNP prepared Nurses Survey Tool was to find out the perception of each DNP prepared nurse and their employer and examine if there were any differences between them. The tool has three sections: (a) demographic information, (b) a list of the 38 competencies within the eight essentials rated on a five-point Likert scale with a "Not Applicable" option, and (c) one open-ended question intended to let them provide thoughts about how DNP degree influenced their practice.

\subsection{Recruitment}

Recruiting flysheets with a link and a QR code to the information letter and survey were distributed at the 2020 AACN Doctoral Education Conference. Following the conference, a recruiting email with a link and a QR code to the same information letter and survey was sent via public e-mails to the attendees of the conference and DNP faculty listed on official university websites across the U.S. This initial email also requested faculty to forward it to others with DNP degree and their employers. After two weeks, a follow-up email was sent to all DNP faculty found on their official university websites requesting them to forward and participate if they had not done before. The recruitment period lasted one month.

\section{Results}

\subsection{Sample}

There were 202 participants that responded with completion of the survey on the SurveyGizmo website provided on the flysheets and emails. The data were analyzed using IBM SPSS Statistics Pack 23.0 software. Table 1 describes the demographic characteristics of the sample including educational background, and work status. 80.2\% $(n=162)$ of the participants $(n=202)$ were DNP prepared nurses, 9.4\% $(\mathrm{n}=19)$ were employers of DNP prepared nurses and $10.4 \%(n=21)$ were DNP prepared nurses and employers of DNP prepared nurses at the same time. Of the sample, $87.1 \%(n=176)$ of the respondents had completed their DNP degree. $4.0 \%(n=8)$ had attained both DNP degree and $\mathrm{PhD}$ degree. $43.6 \%$ reported they had completed their DNP degree 1 to 5 years ago, 37.1\% 6-10 years ago. Data revealed that $46 \%$ of respondents were mainly working in an advanced practice role, $47.5 \%$ spent most of time working in an education role in a university, $1.5 \%$ worked in administration in hospitals or universities, and 5.0\% worked in other roles.

\subsection{Responses for Perceptions of Essentials and Competencies}

Respondents rated their perception of how they met the competencies within the eight Essentials as DNP prepared nurses or how their employers thought they met the competencies through a five-point Likert scale. Examining the Essentials, the mean of the perception of total Essentials was 4.437 ( $\mathrm{SD}=.678)$, which correlated with responses between "strongly agree" and "agree". The lowest mean was 4.289 (SD=.912) for Essential VII (Clinical Prevention and Population Health for Improving the Nation's Health), and the other two lower means was respectively $4.310(\mathrm{SD}=.877)$ for Essential V (Health Care Policy for Advocacy in Health Care) and $4.360(\mathrm{SD}=.779)$ for Essential IV (Information Systems/Technology and Patient Care Technology for the Improvement and Transformation of Health Care). The highest mean was $4.570(\mathrm{SD}=.645)$ for Essential VIII (Advanced Nursing Practice). Details showed in table 2.

When assessing the relationship between the demographic characteristics and the perception of each Essential, there was no significant difference between DNP prepared nurses and their employers for how they rated the Essential I, II, IV, V and VIII as determined by one-way ANOVA. Homogeneity of variances of Essential III, VI, VII, and the total Essential were violated, and therefore a following Welch $\mathrm{F}$ test showed 
there were significant differences between their different identities for Essential III, VI, and the total essential

(respectively, $\mathrm{F}(2,35.261)=5.400, \mathrm{p}=.009, \mathrm{~F}(2,38.387)=$ $6.333, \mathrm{p}=.004, \mathrm{~F}(2,36.207)=5.023, \mathrm{p}=.012)$

Table 1. Demographics.

\begin{tabular}{|c|c|}
\hline Variable & No. $(\%)$ \\
\hline \multicolumn{2}{|l|}{ Identity } \\
\hline A DNP prepared nurse & $162(80.2)$ \\
\hline An employer of DNP prepared nurses & $19(9.4)$ \\
\hline A DNP prepared nurse and an employer of DNP prepared nurses at the same time & $21(10.4)$ \\
\hline \multicolumn{2}{|l|}{ Age } \\
\hline $21-29$ & $2(1.0)$ \\
\hline $30-39$ & $21(10.4)$ \\
\hline $40-49$ & $39(19.3)$ \\
\hline $50-59$ & $75(37.1)$ \\
\hline $60-69$ & $61(30.2)$ \\
\hline 70-79 & $4(2.0)$ \\
\hline \multicolumn{2}{|l|}{ Gender } \\
\hline Male & $21(10.4)$ \\
\hline Female & $181(89.6)$ \\
\hline \multicolumn{2}{|l|}{ Highest level of nursing education } \\
\hline BSN & $1(0.5)$ \\
\hline MSN & $2(1.0)$ \\
\hline DNP & $176(87.1)$ \\
\hline $\mathrm{PhD}$ & $13(6.4)$ \\
\hline Both $\mathrm{DNP}$ and $\mathrm{PhD}$ & $8(4.0)$ \\
\hline Other & $2(1.0)$ \\
\hline \multicolumn{2}{|l|}{ Path to obtaining DNP degree } \\
\hline BSN to DNP & $10(5.0)$ \\
\hline MSN to APRN to DNP & $42(20.8)$ \\
\hline MSN to DNP & $112(55.4)$ \\
\hline $\mathrm{PhD}$ to $\mathrm{DNP}$ & $2(1.0)$ \\
\hline Other & $21(10.4)$ \\
\hline Not applicable & $15(7.4)$ \\
\hline \multicolumn{2}{|l|}{ Time since DNP completion } \\
\hline$<1$ year & $2(1.0)$ \\
\hline $1-5$ years & $88(43.6)$ \\
\hline $6-10$ years & $75(37.1)$ \\
\hline$>10$ years & $18(8.9)$ \\
\hline Not applicable & $19(9.4)$ \\
\hline \multicolumn{2}{|l|}{ If mainly working as an advanced practice role? } \\
\hline Yes & $93(46.0)$ \\
\hline No & $109(54.0)$ \\
\hline Education in University & $96(47.5)$ \\
\hline Administrative in hospital/university & $3(1.5)$ \\
\hline Other & $10(5.0)$ \\
\hline \multicolumn{2}{|l|}{ State practice authority } \\
\hline Full practice & $83(41.1)$ \\
\hline Reduced practice & $39(19.3)$ \\
\hline Restricted practice & $80(39.6)$ \\
\hline
\end{tabular}

Table 2. Doctor of Nursing Practice Essentials/Competencies Combined Responses.

\begin{tabular}{|c|c|c|c|}
\hline $\begin{array}{l}\text { Essentials of Doctoral } \\
\text { Education }\end{array}$ & Description & $\begin{array}{l}\text { Competencies } \\
\text { Items }\end{array}$ & $\begin{array}{l}\text { Mean (Standard } \\
\text { Deviation) }\end{array}$ \\
\hline Essential I & Scientific underpinnings for practice & 3 & $4.567(.708)$ \\
\hline Essential II & $\begin{array}{l}\text { Organizational and Systems Leadership for Quality Improvement and Systems } \\
\text { Thinking }\end{array}$ & 3 & $4.458(.913)$ \\
\hline Essential III & Clinical Scholarship and Analytical Methods for Evidence-Based Practice & 7 & $4.479(.722)$ \\
\hline Essential IV & $\begin{array}{l}\text { Information Systems/Technology and Patient Care Technology for the Improvement } \\
\text { and Transformation of Health Care }\end{array}$ & 5 & $4.360(.779)$ \\
\hline Essential V & Health Care Policy for Advocacy in Health Care & 7 & $4.310(.877)$ \\
\hline Essential VI & $\begin{array}{l}\text { Interprofessional Collaboration for Improving Patient and Population Health } \\
\text { Outcomes }\end{array}$ & 3 & $4.465(.851)$ \\
\hline Essential VII & Clinical Prevention and Population Health for Improving the Nation's Health & 3 & $4.289(.912)$ \\
\hline Essential VIII & Advanced Nursing Practice & 7 & $4.570(.645)$ \\
\hline All Essentials & 1 & 38 & $4.437(.678)$ \\
\hline
\end{tabular}


Table 3. Tamhane Post Hoc Tests.

\begin{tabular}{|c|c|c|c|c|c|}
\hline \multirow{2}{*}{$\begin{array}{l}\text { Essentials of Doctoral } \\
\text { Education }\end{array}$} & \multicolumn{3}{|c|}{ Mean (Standard Deviation) } & \multirow{2}{*}{ Post Hoc Test } & \multirow{2}{*}{ Sig. } \\
\hline & G1 & G2 & G3 & & \\
\hline \multirow[t]{3}{*}{ Essential III } & $4.49(.68)$ & $4.08(1.16)$ & $4.74(.34)$ & $\mathrm{G} 1>\mathrm{G} 2$ & .361 \\
\hline & & & & $\mathrm{G} 1<\mathrm{G} 3$ & $.026^{*}$ \\
\hline & & & & $\mathrm{G} 2<\mathrm{G} 3$ & .077 \\
\hline \multirow[t]{3}{*}{ Essential VI } & $4.48(.84)$ & $4.02(1.17)$ & $4.76(.34)$ & $\mathrm{G} 1>\mathrm{G} 2$ & .294 \\
\hline & & & & $\mathrm{G} 1<\mathrm{G} 3$ & $.017 *$ \\
\hline & & & & $\mathrm{G} 2<\mathrm{G} 3$ & $.042 *$ \\
\hline \multirow[t]{3}{*}{ All Essentials } & $4.43(.67)$ & $4.19(.90)$ & $4.68(.33)$ & $\mathrm{G} 1>\mathrm{G} 2$ & .607 \\
\hline & & & & $\mathrm{G} 1<\mathrm{G} 3$ & $.023 *$ \\
\hline & & & & $\mathrm{G} 2<\mathrm{G} 3$ & .102 \\
\hline
\end{tabular}

$* \mathrm{P}<0.05$

G1 $=$ DNP prepared nurses,

$\mathrm{G} 2=$ Employers,

$\mathrm{G} 3=\mathrm{A}$ DNP prepared nurse and an employer at the same time.

As for Essential III, in table 3, a Tamhane post hoc test revealed that the perception that DNP prepared nurses rated was statistically significantly lower $(4.49 \pm .68, p=.026)$ compared to those working as a DNP prepared nurse and an employer at the same time (4.74 \pm .34$)$. There was no statistically significant difference between the DNP prepared nurses and employers $(\mathrm{p}=.361)$, between employers and those working as a DNP prepared nurse and an employer at the same time $((\mathrm{p}=.072)$.

As for Essential VI, a Tamhane post hoc test revealed that the perception that those working as a DNP prepared nurse and an employer at the same time rated was statistically significantly higher $(4.76 \pm .34)$ compared to DNP prepared nurses (4.48 $\pm .84, \mathrm{p}=.017)$ and other employers (4.02 \pm 1.17 , $\mathrm{p}=.042)$. There was no statistically significant difference between the DNP prepared nurses and employers $(\mathrm{p}=.294)$.

As for the total Essentials, a Tamhane post hoc test revealed that the perception that DNP prepared nurses rated was statistically significantly lower $(4.43 \pm .67, \mathrm{p}=.023)$ compared to those working as a DNP prepared nurse and an employer at the same time (4.68土.33). There was no statistically significant difference between the DNP prepared nurses and employers $(\mathrm{p}=.607)$, employers and those working as a DNP prepared nurse and an employer at the same time $((\mathrm{p}=.102)$.

There was no significant difference between their ages, gender, and the time after their DNP completion for their perception of every Essential as determined by one-way ANOVA.

\section{Discussion}

As a whole, respondents rated the total Essentials with a mean score of 4.437 , between "strongly agree" and "agree". Higher mean scores was rated for five of those Essentials, Essential I, II, III, VI, and VIII, which showed that they perceived that they mastered most of the Essentials and competencies. However, a lowest mean (4.289) was rated for the perception of Essential VII (Clinical prevention and population health for improving the nation's health), which means they perceived this competency was the weakest one that they have mastered. Issel et al. [9]. and Zahner et al. [10]. also have conducted similar studies on competence among public health nurses (PHNs) and found that many PHNs do not have enough capacity to function their roles in public health. Both Issel et al.'s study of PHNs working at local health departments in Illinois and Zahner et al.'s multiyear study on linking education and practice for excellence in public health nursing have found many PHNs were able to work proficiently in only one filed of practice - linking people to services. This calls for our deep thought that population health emphasis might be a largely missing component in nursing education broadly and especially in DNP education which is largely focused ARNP and needs a better foundation in DNP curricula.

This finding that DNP prepared nurses felt less competent in the area of public health informs all the faculty and staff working in leadership positions in health care that they should take more effort to integrate prevention and population health concepts and social determinants of health into areas of nursing curricula to equip nurses to implement prevention strategies in practice. Deans and directors of schools and programs of nursing in Washington State have discovered this potential need for health care system in the U.S in 2017 after many years of development of DNP programs [11]. Based on the fact that lower public health status and higher mortality rates happen in America than those in peer countries over the world [12]. and the increasing need to equip nurses the knowledge that prioritize prevention efforts over treatment [13]., deans and directors of schools and programs of nursing in Washington State published a white paper [14]. to facilitate integrating population health concepts and social determinants of health into all areas of their respective nursing curricula, after a statewide collaboration work through approximately one year of meetings and communications. The white paper was ratified by 38 deans and directors representing all 14 baccalaureate and higher degree nursing programs across 19 campuses in Washington State in 2017. Nurses should not only focus on implementing advanced nursing practice and evidence-based practice to improve patient outcomes but also heighten the awareness of public prevention for population health and address the gaps in care of individuals or populations. Especially the COVID-19 pandemic in 2019 and 2020 undoubtedly gave us a lesson that disease and epidemic 
prevention efforts should be significantly taken and strongly strengthened in the future no matter which place, which community or which country. Strengthening public health capacity should be done as a foundation, recommended Harvard Global Health Institute [15].

The results also showed that respondents felt less competent in two other essentials, which were Essential V (health care policy for advocacy in health care) with a mean score of 4.310 , and Essential IV (information systems/technology and patient-care technology for the improvement and transformation of health care) with a mean score of 4.360 . Some scholars pointed out that DNP prepared nurses were required to be fluent in health policy and competent in using the technology of today as the desire for preventive, population-focused health outcomes were growing [16]. AACN established a Faculty Policy Think Tank (FPTT) to develop recommendations for improving nursing students at all levels and nurses' engagement in health care policy and those recommendations were published in 2017 [17]. De Cordova et al. [18]. also suggested that more research on how health care policy courses were delivered should be conducted to impact future health care policy and advocacy efforts, even though there were already some health care policy courses included into nursing curricula in the U.S. Luo et al. [19]. developed a 12-step technology training protocol to improve nurses' competencies in utilizing today's technologies and bring up their interests and enthusiasm to adopt new technologies. More methods, experiments, and research to evaluate, promote, and stimulate nurses' competencies in applying new technologies into practice should be conducted and popularized.

Those working as a DNP and an employer at the same time rated higher than DNP prepared nurses themselves or employers for Essential III, VI, and the total Essentials revealed that a DNP prepared nurse grown up as an employer shows more confident with clinical scholarship and analytical methods for evidence-based practice, interprofessional collaboration for improving patient and population health outcomes, and the overall competencies. A DNP prepared nurse and employer may accept more about what they can do on their positions and utilize those competencies more easily.

Undoubtedly, a DNP degree is the ultimate academic degree for those who seek the highest level of practice in nursing and is thought to be the best way to cultivate the most qualified nurses in practice. However, capabilities of mastering scientific knowledge, leadership, evidence-based practice, interprofessional collaboration, and advanced practice are not the only significant competencies that DNP nurses should attain, or educators should teach. Competencies in using new information technologies, influencing health care policy and implementing preventive interventions for population health are easily overlooked for more clinical skills in DNP programs but are crucial for effective DNP practice. More evaluation research of every aspect of before/after DNP programs should be conducted while developing at the same time in the U.S, more strategies to improve every competency within DNP programs should be developed as well.

These findings also give enlightenment to those countries that want to start and develop DNP programs. Firstly, the fact that DNP prepared nurses perceive that they are meeting the competencies set forth by DNP programs based on this study of self-perceived competencies, DNP programs are regarded as an effective and efficient way to make DNP nurses competent. Moreover, these findings provide valuable information as DNP programs prepare, adjust, re-balance, and level up every domain of competencies in curricula at the beginning of starting DNP programs. For example, in Australia, scholars recommended that a perhaps Australia Nurse Practitioner faculty group could be formed as a subgroup of the Council of Deans Nursing and Midwifery to design a customized Professional Doctorate program for their Nurse Practitioners [20]. In the United Kingdom, an Oxford-style team debate was adopted and developed into their diverse DNP courses including health policy, informatics, finance, and marketing strategies, to increase student capabilities for mentoring of global health care [21]. In China, a deep look at the current education and examination system, and then determining how to efficiently integrate advanced practice competencies into nursing curricula are necessary and urgent to implement for future DNP education.

\section{Conclusion}

This Competencies of DNP prepared Nurses Survey Tool and research indicated DNP prepared nurses perceived that they are consistently engaged and well-practiced in competencies associated with Essentials I, II, III, VI, VIII and lesser extent with Essentials IV, V, VII. Those working as a DNP and an employer at the same time show more confident than DNP prepared nurses themselves or employers for Essential III, VI, and the total Essentials. Informatic technologies, health care policy, and population health are the three domains on which educators should put more emphasis. More useful and practical tools should be designed and developed to examine more aspects of DNP competencies. Universities or countries that haven't initiated a DNP program should ingeniously integrate each competency into nursing curricula and universities that are providing DNP programs should appropriately adjust their curricula to fit every competency.

However, some limitations should be noted. First, a convenience sample was utilized and only included DNP prepared nurses that we were able to reach on their university official websites, and those who participated the 2020 AACN DNP conference, a large number of DNP prepared nurses who work at advanced nursing practice positions were not included, which cause a limited sample size. We recommended organizations, such as AACN, American Nurses Association, state nursing faculty groups or others, should conduct larger studies to assess more about DNP programs. In addition, we used self-report data instead of observational data. Objective assessment would be recommended for future studies, though observation of a large group of participants across the nation would be much more problematic. 


\section{References}

[1] American Association of Colleges of Nursing. (2004). AACN Position Statement on the Practice Doctorate in Nursing.

[2] American Association of Colleges of Nursing. (2006). The essentials of doctoral nursing education for advanced practice.

[3] American Association of Colleges of Nursing. (2019). Fact Sheet: The Doctor of Nursing Practice (DNP).

[4] Auerbach DI, Martsolf G, Pearson ML, Taylor EA, Zaydman M, Muchow A, Spetz J and Dower C. (2015). The DNP by 2015 A Study of the Institutional, Political, and Professional Issues that Facilitate or Impede Establishing a Post-Baccalaureate Doctor of Nursing Practice Program. RAND Health.

[5] Pritham UA and White P. Assessing DNP impact. (2016). The Nurse Practitioner, 41 (4): 44-53.

[6] Beeber AS, Palmer C, Waldrop J, Lynn MR and Jones CB. (2019). The role of Doctor of Nursing Practice-prepared nurses in practice settings. Nursing Outlook, 67 (4), 354-364.

[7] Fu M and Zhang Y. (2015). Enlightenment of doctor of nursing practice program in America on development of advanced nursing practice in China. Chinese Nursing Research, 29 (3A), 773-775.

[8] Christiansen B and Champion JD. (2018). Examining Doctor of Nursing Practice Clinical Competency. The Journal for Nurse Practitioners, 14 (5), e93-e100.

[9] Issel LM, Baldwin KA, Lyons RL and Madamala K. (2006). Self- reported competency of public health nurses and faculty in Illinois. Public Health Nursing, 23 (2), 168-177.

[10] Zahner SJ and Henriques JB. (2014). Public health practice competency improvement among nurses. American Journal of Preventive Medicine, 47 (5 Suppl. 3), S352-S359.

[11] Hermer J, Hirsch A, Bekemeier B, Nyirati C, Wojnar D, Wild L, Dotson JAW, Smith S, Griffin-Sobel JP and Oneal G. (2020). Integrating population health into nursing education: The process of gaining commitment from Washington's nursing deans and directors. Journal of Professional Nursing, $36(2), 6-12$.
[12] National Research Council and Institute of Medicine. In S. H. Woolf, L. Aron, \& Committee on Population, Division of Behavioral and Social Sciences and Education, and Board on Population Health and Public Health Practice, Institute of Medicine (Eds.). (2013). U.S. health in international perspective: Shorter lives, poorer health. Panel on understanding cross-national health differences among high-income countries. Washington, DC: The National Academies Press.

[13] Storfjell J, Winslow B and Saunders JSD. (2017). Catalysts for change: Harnessing the power of nurses to build population health in the 21 st century.

[14] Deans and Directors of Schools and Programs of Nursing in Washington State. (2017). The future of nursing education: Ensuring a population health focus in nursing education in Washington state.

[15] Harvard Global Health Institute. (2018). Global Monitoring of Disease Outbreak Preparedness: Preventing the Next Pandemic. Harvard University, Cambridge, MA.

[16] Garritano N and Stec M. (2019). Leveraging Technology to Enhance Doctor of Nursing Practice Student Health Policy Engagement. Nurse Educator, 44 (4), 192-196.

[17] American Association of Colleges of Nursing. (2017). Faculty Policy Think Tank: Report and Recommendations.

[18] De Cordova PB, Steck MBW and Vermeesch A. (2018). Health policy engagement among graduate nursing students in the United States. Nursing Forum, 1-6.

[19] Luo S and Kalman M. (2018). A technology training protocol for meeting QSEN goals: Focusing on meaningful learning. Nursing Forum, 53 (1), 20-26.

[20] Cashin, A. (2017). A scoping review of the progress of the evolution of the Doctor of Nursing Practice in the USA to inform consideration of future transformation of Nurse Practitioner education in Australia. Collegian.

[21] Naomi E, Karen F and Michelle B. (2016). Utilizing team debate to increase student abilities for mentoring and critical appraisal of global health care in doctor of nursing practice programs. Journal of Professional Nursing, Vol 32, No. 3 (May/June), 2016: pp 224-234. 